Academic Platform Journal of Engineering and Science

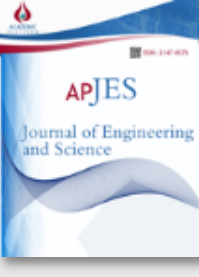

\title{
Demir Çelik Sektöründe Hibrid DEMATEL ve TOPSİS-ELECTRE Yöntemleri ile Hata Türleri ve Etkileri Analizi
}

\author{
*1 Fuat Şimşir, ${ }^{2}$ Halil İbrahim Demir, ${ }^{3}$ Sena Azdemir \\ ${ }^{1}$ Karabük Üniversitesi, Mühendislik F., Endüstri Müh. Böl., Karabük, fuatsimsir@karabuk.edu.tr \\ ${ }^{2}$ Sakarya Üniversitesi, Mühendislik F., Endüstri Müh. Böl., Sakarya, hidemir@ sakarya.edu.tr \\ ${ }^{3}$ Karabük Üniversitesi, Mühendislik F., Endüstri Müh. Böl., Karabük, sena_azdemir@hotmail.com iD
}

Araştırma Makalesi

Geliş Tarihi: 06.02.2018

Kabul Tarihi: 29.08.2018

$\ddot{O} z$

Üretim sektöründe süreç içinde oluşan hatalar zamanında tespit edilemediği takdirde kalite yetersizliğini ortaya çıkaracağından müşteri kayıplarına neden olmaktadır. Üretici tarafinda ise gerekli kaliteye sahip olmayan hatalı ürünler için kullanılmış olan kaynaklar israf edilmiş olacak ve dolayısıyla zaman ve para kaybına neden olacaktır. Hataları minimize edebilmek için; hataların tespitlerinin yapılması, sebeplerinin bulunması ve önceliklendirilmelerinin gerçekleştirilmeleri gerekmektedir. Bu amaçla uygulama kolaylığı olan Hata Türleri ve Etkileri Analizi(HTEA) çokça tercih edilen hata tespiti tekniklerindendir. Bu çalışmada, incelenen haddehanede oluşan hata türlerinin ve etkilerinin belirlenmesinde Klasik HTEA yönteminin uygulanmasıyla Risk Öncelik Sayısı (RÖS) değerlerine göre hatalar sıralanmıştır. RÖS değerinin hesabı için "Olasıllk", "Şiddet" ve "Saptama" değerleri kullanılmaktadır. Bu üç değer kriter olarak kullanılarak, TOPSİS ve ELECTRE metotları ile de hataların öncelik sıralaması bulunmuştur. TOPSIS ve ELECTRE tekniklerinin uygulanmasında kullanılacak olan kriter ağırlıklarını belirlemede ise DEMATEL metodu tercih edilmiştir. Uygulamalar neticesinde, her üç yöntemde de ilk dört hatanın sıralaması aynı çıkmış, takip eden sıradakilerde farklılıklar olduğu gözlemlenmiştir. Böylece, hatalarının önceliklendirilmesi için üç farklı yöntemin karşılaştırmalı olarak değerlendirilebilmesi sağlanmıştır.

Anahtar kelimeler: Hata Türleri ve Etkileri Analizi, DEMATEL, TOPSİS, ELECTRE

\section{Failure Mode and Effects Analysis With Hybrid DEMATEL and TOPSIS- ELECTRE Methods in Iron Steel Sector}

\author{
*1 Fuat Şimşir, ${ }^{2}$ Halil İbrahim Demir, ${ }^{3}$ Sena Azdemir \\ ${ }^{1}$ Karabük University, Industrial Engineering Department, Karabuk-TURKEY, fuatsimsir@karabuk.edu.tr \\ ${ }^{2}$ Sakarya University, Industrial Engineering Department, Sakarya-TURKEY, hidemir@sakarya.edu.tr \\ ${ }^{3}$ Karabük University, Industrial Engineering Department, Karabuk-TURKEY, sena_azdemir@ hotmail.com
}

\begin{abstract}
Errors that occur in the production process in the manufacturing sector cause customer losses because they will cause quality insufficiency if not detected in time. On the manufacturer side, the resources used for faulty products which do not have the necessary qualities will be wasted and will cause time and money loss. To minimize errors; the detection of faults, the discovery and prioritization of reasons are required. For this purpose, Failure Mode and Effects Analysis (FMEA) technique, which is easy to implement, is one of the most preferred error detection techniques. In this study, errors were classified according to the Risk Priority Number (RPN) values by applying the Classical FMEA method in determining the types of errors and their effects in the examined rolling stock. "Probability", "Intensity" and "Detection" values are used for the calculation of the RPN value. Using these three values as criteria, and using TOPSIS and ELECTRE methods, the priority order of errors are found. DEMATEL method has been preferred in determining the criteria weights to be used in the application of TOPSIS and ELECTRE techniques. As a result of the applications, the order of the first four errors was the same in all three methods, and the differences were observed in the following rows. Thus, it is possible to compare three different methods for prioritization of failures.
\end{abstract}

Keywords: Failure Mode and Effects Analysis, DEMATEL, TOPSIS, ELECTRE

*Sorumlu Yazar: Fuat Şimşir: Karabük Üniversitesi, Mühendislik Fakültesi, Endüstri Mühendisliği Bölümü, Demir Çelik Kampüsü, Karabük, fuatsimsir@karabuk.edu.tr, Tel: 03704332021 / D: 3940 


\section{GİRIŞ}

Üretim sektöründe, öncelikle pazarda tutunabilmek sonrasında ise rekabet üstünlüğü sağlayarak pazar payını daha da artırabilmek için üretici müşteriye kaliteli ürün sunmalıdır. $\mathrm{Bu}$ üstünlüğün elde edilebilmesi ve sürdürülebilmesi, hataların doğru bir öncelikle zamanında tespit edilmesiyle beklenen kalitenin gerçekleştirilmesine bağlıdır. Demir çelik üretimindeki hatalar, müşteri açısından memnuniyetsizliğe üretici açısından ise zaman ve para kaybına neden olmaktadır. Birçok firma, zamanlarını hataları minimize etmeye çalışmakla geçirmektedir.

Hatayı minimize etmenin ilk adımı hatanın ne olduğu ve neden kaynaklandığını bilmektir. Kaliteli ürün üretimi için hatası minimum olan bir süreç gereklidir. HTEA (FMEA= Failure Modes And Effects Analysis) tekniği; hataları ortaya çıkmadan önlemeyi amaçlayan, uygulama kolaylığ olan, çokça tercih edilen, sayısal temelli bir hata tespit yöntemidir.

HTEA'da hata önceliklerini belirleyebilmek için; "Ortaya çıkma (O) , Şiddet (Ş) ve Saptama (S)"parametreleri ile RÖS değerleri hesaplanır. Ortaya Çıkma, hatanın sıklığını; Şiddet, hatanın etkisini; Saptama, hatayı ürün müşteriye ulaşmadan tespit etme yeteneğini göstermektedir.

HTEA'nın uygulama kolaylığı ve hızlı sonuçlar vermesi sebebiyle literatürde; geleneksel HTEA ve farklı yöntemlerin HTEA uyarlamaları ile yapılmış çeşitli çalışmaların mevcut olduğu görülmüştür. Teng ve Ho, Tasarım HTEA ve süreç HTEA'sını, güvenilirlik tahminleri ve tedarikçi kalite raporları aracılığıyla entegre etmişlerdir [1]. Aran, çalışmasında motor pistonlarına uygulanan Proses HTEA'sını ele alıp, süreçleri incelemiştir. Piston üretim sürecinde karşılaşılan hatalar HTEA tekniğine göre analiz edilmiş, tekniğin firmanın kalite fonksiyonlarını iyileştirme konusundaki başarısı gösterilmiştir [2].

Tay ve Lim, RÖS değerlerinin bulunması için bulanık kural sayısını azaltarak daha basit bir Bulanık Mantık temelli sistem önermişlerdir [3]. Taşan, çalışmasında bir risk değerlendirme ve güvenilirlik metodu olan HTEA'y1 detaylı olarak araştırmış ve bir otomotiv sanayi işletmesinde güvenilirlik bağlantıları ile beraber Tasarım HTEA'sı uygulamasını gerçekleştirmiştir [4].

Liu ve arkadaşları; Ortaya çıkma (O) , Şiddet (Ş) ve Saptama (S)değerlerinin derecelendirmelerini ve ağırlıklarını belirlemek için yamuk veya üçgen bulanık sayılarla ifade edilen dilsel değişkenler kullanmıştır. Bulanık küme teorisine ve VIKOR yöntemine dayanan bulanık bir HTEA ile geleneksel HTEA'nın bazı kısıtlamalarını ortadan kaldırmayı amaçlayan hata türlerinin önceliklendirilmesini amaçlamışlardır [5].

Kutlu ve Ekmekçioğlu, bulanık AHP ile entegre bulanık TOPSİS uygulayarak, HTEA için uzmanların dilsel değişkenleri kullanarak $\mathrm{O}$, Ş ve S'yi belirlemesine izin veren bulanık bir yaklaşım önermişlerdir[6].
Liu ve arkadaşları, çalışmalarında geleneksel risk öncelik Sayısı (RÖS) hesaplama yöntemindeki aksaklıkları ele almış olan mevcut akademik çalışmaları gözden geçirmişler ve kullanılan literatürü mevcut yaklaşımlara göre sınıflandırmışlardır. 1992'den 2012'ye kadar uluslararası dergilerde yer alan ilgili makaleleri analiz etmişlerdir [7]

Yapılmış olan bu çalışmadan, konu kapsamındaki geniş bir literatürün gözden geçirilmesi imkanı bulunmuş ve incelenen çalışmalarda DEMATEL-ELECTRE ve TOPSISS tekniklerinin birlikte kullanımının olmadığ 1 görülmüştür. Chen ve $\mathrm{Wu}$, Belediye katı atık geri dönüşüm tesislerindeki genel arızaları saptamak, sınıflandırmak ve analiz etmek için klasik HTEA uygulaması yapmışlardır [8].

Liu ve arkadaşları, risk faktörü ağırlıklandırması için bulanık analitik hiyerarşi süreci (AHP) ve entropi yönteminin entegrasyonunu kullanarak bulanık VIKOR yöntemine dayalı yeni bir yaklaşım önermişlerdir [9].

Zhou ve Thai, RÖS değerlerinin hesaplanmasında Bulanık Mantık ve Gri İlişkisel Analiz kuramlarını uygulamışlar, tankerlerdeki ekipman arızaları tahmini problemi üzerinden sonuçları karşılaştırmışlar, sonuçların her iki yöntemde de benzer olduğu sonucuna varmışlardır [10].

Tooranloo ve Ayatollah, sezgisel bulanık yaklaşıma dayalı HTEA için yeni bir model önermişlerdir. Önerilen model, belirsiz kavramlarla ve yetersiz verilerle çalışılırken hata türlerini değerlendiren bir araç sağlar. Model, internet bankacılığı hizmetlerinin kalitesi için hata türlerini inceleyen bir vaka çalışmasında test edilmiştir [11].

Yazdi ve arkadaşları, Klasik HTEA'da RÖS değerlerinin hesaplanmasında kullanılan kesin puanlama yönteminin eksikliklerinin literatürde de çokça ifade edilmesinden yola çıkarak Klasik HTEA ile geliştirdikleri Bulanık HTEA'nın havacılık alanında karşılaştırmalı incelemesini yapmışlar ve Bulanık HTEA'nın daha güvenilir sonuçlar verdiğini söylemişlerdir [12].

Jiang ve arkadaşları, geleneksel HTEA'nın eksikliklerinin yeni bir bulanık kanıt yöntemi temel alan bir HTEA modeli ile giderilmesine çalıştıklarını ifade etmişılerdir. Risk faktörlerinin riskleri bulanı üyelik derecesi ile değerlendirilmiş; $\mathrm{O}$, Ş ve S özellik bilgilerinin DempsterShafer (D-S) kanıt teorisi ile hesaplanmasi neticesinde hata türlerinin sıralamasını önermişlerdir [13].

Klasik HTEA'da RÖS değerinin hesaplamasında ortaya çıkan eksiklikleri ortadan kaldırmak amacıyla farklı modeller geliştirilmiş ve literatürde incelenen makalelerde en çok kullanılan yöntemlerin ÇKKV yöntemleri olduğu tespit edilmiştir. Bu çalışmada ise, önce Klasik HTEA uygulanarak RÖS değerlerine göre hatalar sıralanmıştır. Bunun yanı sıra, belirlenen hata türlerinin sıralanmasında ölçüt olarak kabul edilen RÖS değerinin hesabı için kullanılan Olasılık, Şiddet ve Saptama değerleri, kriter 
kabul edilerek çok kriterli karar verme tekniklerinden TOPSIS ve ELECTRE metodları ile de hatalar analiz edilmiştir. TOPSIS ve ELECTRE tekniklerinin uygulanmasında kullanılacak olan kriter ağırlıklarının daha sistematik bir şekilde belirlenmesi için de DEMATEL yöntemi tercih edilmiştir.

DEMATEL, ELECTRE ve TOPSIS'in bu şekilde birlikte kullanılması ile Klasik HTEA'nın uygulama kolaylığını, ÇKKV yöntemlerinin sağlamış olduğu güçlü yönleri ile birleștirerek, RÖS hesabının dezavantajlı yönlerine karşı daha etkin bir hata öncelik sıralaması yapılabilmesi amaçlanmıştır.

Yöntemler haddeleme ile üretim yapan bir demir-çelik tesisinde uygulanarak, sonuçlar bölüm 4'te karşılaştırmalı olarak verilmiştir.

Çalışmanın bundan sonraki akışında ise; bölüm 2'de Metodoloji, bölüm 3'te Uygulama, bölüm 4'te Yöntemlerin karşılaştırmalı değerlendirilmesi, bölüm 5'te ise sonuçlara yer verilmiştir.

\section{METODOLOJí}

Çalışmada, ilk olarak süreçteki hataların tespit edilmesinin ardından üç farklı teknik (Şekil 1) kullanılarak hataların önceliklendirilmesinin karşılaştırılmalı olarak değerlendirilmesi sağlanmıştır. Kullanılan teknikler aşağıdaki şekildeki gösterildiği gibidir:

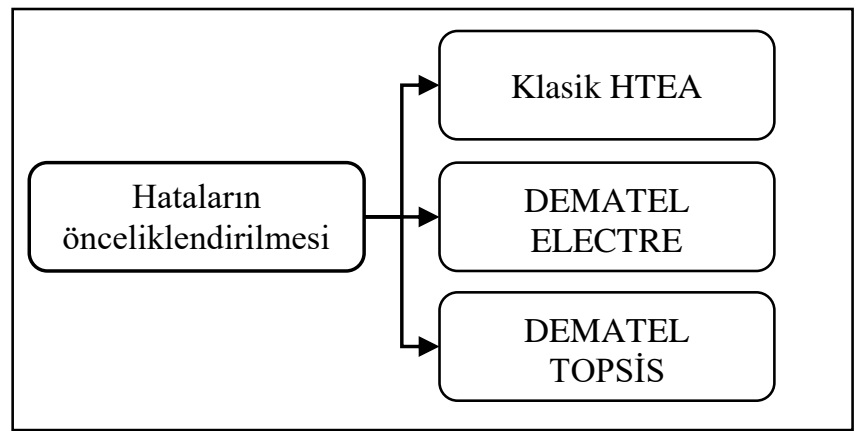

Şekil 1. Kullanılan Teknikler

Uygulamanın birinci adımında klasik HTEA uygulanmıştır. Klasik HTEA uygulanması için süreçte tespit edilen hataların bilgilerinin toplanmasının ardından, her bir hata için Ortaya Çıkma, Şiddet ve Saptama değerleri belirlenmiştir. Ardından, Formül 1 kullanılarak elde edilen Risk Öncelik Sayısı (RÖS) değeri temel alınarak hatalar sıralanıp önceliklendirilmiştir (Şekil 2).

Uygulamanın ikinci adımı; TOPSİS ve ELECTRE yöntemlerinin, ayrı ayrı DEMATEL yöntemi ile hibrid hale getirilerek hataların önceliklendirilmesi işlemini kapsamaktadır. Bu sebeple aşağıda ki alt bölümlerde bu yöntemlerin adımlarının açıklanmasına yer verilecektir.

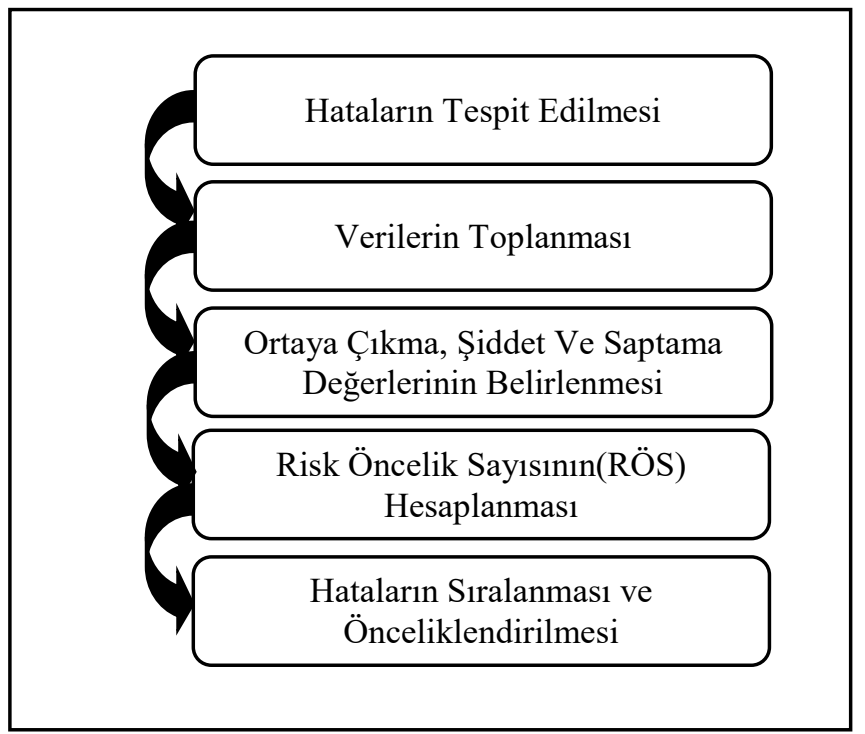

Şekil 2. HTEA Çalışma Metodolojisi

\subsection{HTEA Tekniği}

HTEA, bir üründe oluşabilecek tasarım ve/veya proses kökenli tüm hata türlerinin sistematik olarak analiz edilmesidir. Her türlü hata için, müşteri üzerinde oluşturacağı olası etkilere göre analizler yapılır. Bu analizlerin hepsi ürün daha pazara çıkmadan önce, hatta tasarım ve/veya deneme üretimleri sirasında yapılır ve bu sayede herhangi bir hatanın daha oluşmadan önlenmesini sağlamakla birlikte müşteriye ulaşmadan hatanın tespit edilmesini sağlar. Bu yöntem sayesinde operasyonlardaki hataların önlenmesi, risklerin en aza indirilmesi ile verimliliğin artırılarak maliyetlerin düşürülmesi sağlanmış ve rekabet gücü kazanılmış olacaktır [14].

HTEA yönteminde hata önceliklerini belirlemede üç bileşen vardır.

$$
\begin{aligned}
& \text { - Ortaya çıkma (O) } \\
& \text { - Şiddet (Ş) } \\
& \text { - Saptama (S) }
\end{aligned}
$$

Ortaya Çıkma, hatanın sıklığını; Şiddet, hatanın etkisini; Saptama, hatayı ürün müşteriye ulaşmadan tespit etme yeteneğini gösterir. RÖS değeri ise bu üç bileşenin değerlerinin çarpılması ile hesaplanır:

$$
\begin{aligned}
& \text { Risk Öncelik Sayısı }(\text { RÖS })= \\
& \text { Ortaya Çıkma }(\mathrm{O}) \times \text { Şiddet }(\text { Ş }) \times \text { Saptama }(\mathrm{S})
\end{aligned}
$$

Klasik HTEA'da Ortaya Çıkma, Şiddet ve Saptama değerleri için 1-10 arasında değişen puanlama ile ölçek tabloları mevcuttur [5]. Tablo 1 ve Tablo 2'de riskin Ortaya Çıkma ve Şiddeti arttıkça derecesinin arttığı görülmektedir. Ancak Tablo 3'te verilen Saptama dereceleri için durum farklıdır. Bir riskin fark edilmesi ne kadar zor ise derecesi o kadar yüksek olmaktadır. 
Tablo 1. "Ortaya Çıkma” Derecelendirme Tablosu

\begin{tabular}{|l|c|c|}
\hline \multicolumn{1}{|c|}{ Hata Olasılığı } & $\begin{array}{c}\text { Olası Hata } \\
\text { Oranları }\end{array}$ & Derece \\
\hline Oldukça yüksek & $1 / 2$ ‘den fazla & 10 \\
\hline Çok yüksek & $1 / 3$ & 9 \\
\hline Yüksek & $1 / 8$ & 8 \\
\hline Kismen yüksek & $1 / 20$ & 7 \\
\hline Kısmen orta & $1 / 80$ & 6 \\
\hline Orta & $1 / 400$ & 5 \\
\hline Kısmen düşük & $1 / 2000$ & 4 \\
\hline Düşük & $1 / 15000$ & 3 \\
\hline Çok düşük hemen & $1 / 150000$ & 2 \\
\hline $\begin{array}{l}\text { Hemen } \\
\text { olanaksız }\end{array}$ & $\begin{array}{c}1 / 1500000 ’ d e n \\
\text { büyük }\end{array}$ & 1 \\
\hline
\end{tabular}

Şiddet değeri, potansiyel hatanın diğer bileşene, alt sisteme, sisteme ya da müşteriye olan etkisini belirten değerdir [3]. Tablo 2'de 1-10 arası puanlama sistemi ile Şiddet Derecelendirme değerleri görülebilir [17] .

Tablo 3'de gösterildiği gibi 1-10 arası puanlama sistemi ile hatanın Saptama derecesi belirtilir[17].

Saptama değeri de, şiddet ve ortaya çıkma değeri belirlenirken yapıldığı gibi yine geçmiş kayıtların incelenmesi ve takımın tecrübeleri kullanılarak belirlenir [18]

Tablo 2. Şiddet Derecelendirme Tablosu

\begin{tabular}{|c|c|c|c|}
\hline SINIF & ETKİ & KRITTER & DERECE \\
\hline \multirow{3}{*}{ 1.Sinıf } & Tehlikeli & $\begin{array}{l}\text { Emniyetle ilgili arıza, yasalara uyumsuz bir arıza. Hata herhangi bir ikaz } \\
\text { olmadan meydana gelir }\end{array}$ & 10 \\
\hline & Ciddi & $\begin{array}{l}\text { Emniyetle ilgili arıza, yasalara uyumsuz bir arıza. Hata herhangi bir ikazla } \\
\text { meydana gelir }\end{array}$ & 9 \\
\hline & Çok büyük & Üründe temel fonksiyon kaybı. Ürünün tamamı hurdaya çıkar. & 8 \\
\hline \multirow[b]{2}{*}{ 2.Sinif } & Büyük & $\begin{array}{l}\text { Ürün/süreç üzerinde büyük etki. Ürün kullanılamaz. Üretimin ayıklanması ve bir } \\
\text { bölümün (\%100’den az) hurdaya ayrılması gerekir. }\end{array}$ & 7 \\
\hline & Önemli & $\begin{array}{l}\text { Parçanın yeniden işlenmesine neden olur Ürün performansının derecesi } \\
\text { düşmüştür. Ürün çalışmaktadır fakat kolaylık/rahatlık sağlayan bazı parçalar } \\
\text { çalışmaz }\end{array}$ & 6 \\
\hline \multirow[t]{2}{*}{ 3.Sinif } & Orta & $\begin{array}{l}\text { Ürün performansı veya süreç üzerinde orta şiddette etki. Müşteri bazı } \\
\text { rahatsızlıklar duyar. Kolaylık/rahatlık sağlayan parçalar düşük performansla } \\
\text { çalışırlar. }\end{array}$ & 5 \\
\hline & Küçük & $\begin{array}{l}\text { Ürün performansı veya proses üzerinde küçük şiddette etki. Hata müşteri } \\
\text { tarafından fark edilir ve ürün kullanımında bazı rahatsılıklar yaşanır. }\end{array}$ & 4 \\
\hline \multirow{3}{*}{ 4.Sinif } & Önemsiz & $\begin{array}{l}\text { Ürün performansı veya proses üzerinde önemsiz etki. Hata müşteri tarından fark } \\
\text { edilir. }\end{array}$ & 3 \\
\hline & Çok önemsiz & $\begin{array}{l}\text { Ürün performansı veya proses üzerinde önemsiz etki. Hata müşteri tarafından } \\
\text { fark edilmez. }\end{array}$ & 2 \\
\hline & Etkisi yok & Ürün performansı veya proses üzerinde hiç etkisi yok & 1 \\
\hline
\end{tabular}

Tablo 3. Saptama Tablosu

\begin{tabular}{|l|l|c|}
\hline \multicolumn{1}{|c|}{ SAPTAMA } & \multicolumn{1}{c|}{ KRITER } & DERECE \\
\hline Hemen hemen imkânsız & Tespit etme imkânı yok. & 10 \\
\hline Çok zor & Kontrollerin hata türünü belirlemesi çok zor & 9 \\
\hline Zor & Kontrollerin hata türünü belirlemesi zor & 8 \\
\hline Çok az & Kontrollerin hata türünü belirlemesi çok azdır. & 7 \\
\hline Az & Kontrollerin hata türünü belirlemesi azdır. & 6 \\
\hline Orta & Kontrollerin hata türünü belirlemesi ortadır. & 5 \\
\hline Ortanın üstü & Kontrollerin hata türünü belirlemesi ortanın üstündedir. & 4 \\
\hline Yüksek & Kontrollerin hata türünü belirlemesi yüksektir. & 3 \\
\hline Çok yüksek & Kontrollerin hata türünü belirlemesi çok yüksektir. & 2 \\
\hline Hemen hemen kesin & Kontrollerin hata türünü belirlemesi hemen hemen kesindir. & 1 \\
\hline
\end{tabular}




\subsection{DEMATEL Metodu}

DEMATEL metodu Cenova Battele Enstitüsü tarafindan karmaşık "dünya problemlerini" analiz etmek amacı ile geliştirilmiştir. $\mathrm{Bu}$ yöntem, bir yapısal modeli düzenlemek için uzmanların bilgisini kullanmaktadır. Kriterler arasındaki ilişkiler, ikili karşılaştırma ölçeği kullanılarak uzman grup tarafindan belirlenmektedir. Puanlamalar 0-3 veya 0-4 aralığında yapılabilmektedir(Tablo 4).

Uzmanlar, verdikleri sayısal değerlerle, bir kriterin diğerini ne kadar etkilediğini belirtmektedir [19]. DEMATEL metodunun aşamaları, maddeler halinde aşağıda verilmiştir.

Tablo 4. DEMATEL İkili Karşılaştırma Skalası

\begin{tabular}{|c|c|}
\hline Sayısal Değer & Tanım \\
\hline 0 & Etkisiz \\
\hline 1 & Düşük etki \\
\hline 2 & Orta derecede etki \\
\hline 3 & Yüksek derecede etki \\
\hline 4 & Çok yüksek derecede etki \\
\hline
\end{tabular}

1. Adım: Direkt İlişki Matrisinin (A) Oluşturulması

$$
\mathrm{A}=\left[\begin{array}{ccc}
0 & \cdots & \mathrm{a}_{1 \mathrm{n}} \\
\mathrm{a}_{21} & 0 & \mathrm{a}_{2 \mathrm{n}} \\
\vdots & \ddots & \vdots \\
\mathrm{a}_{\mathrm{n} 1} & \cdots & 0
\end{array}\right]
$$

2. Adım: Normalleştirilmiş Direkt İlişki Matrisinin (M) Oluşturulması

$$
\begin{aligned}
& \mathrm{M}=\mathrm{k} \times \mathrm{A} \\
& \mathrm{k}=\operatorname{Min}\left(\frac{1}{\max \sum_{\mathrm{j}=1}^{\mathrm{n}}\left|\mathrm{a}_{\mathrm{ij}}\right|}, \frac{1}{\max \sum_{\mathrm{j}=1}^{\mathrm{n}}\left|\mathrm{a}_{\mathrm{ij}}\right|}\right) \\
& \mathrm{i}, \mathrm{j} \in\{1,2,3, \ldots \ldots ., \mathrm{n}\}
\end{aligned}
$$

3.Adım:Toplam İlişki Matrisinin (T) Oluşturulması

$$
\mathrm{T}=\mathrm{Mx}(\mathrm{I}-\mathrm{M})^{-1}
$$

4. Adım:T Matrisinin Satır Toplamlarının $\left(D_{i}\right)$ Ve Sütun Toplamlarının $\left(R_{j}\right)$ Hesaplanması

$$
\begin{aligned}
& \mathrm{T}=\left[\mathrm{T}_{i, j}\right]_{n \times n} \quad i, j \in\{1,2,3, \ldots . \mathrm{n}\} \\
& \mathrm{D}_{\mathrm{i}}=\sum_{\mathrm{j}=1}^{\mathrm{n}} \mathrm{T}_{\mathrm{i}, \mathrm{j}} \\
& \mathrm{R}_{\mathrm{j}}=\sum_{\mathrm{i}=1}^{\mathrm{n}} \mathrm{T}_{\mathrm{i}, \mathrm{j}}
\end{aligned}
$$

5. Adım: Her Bir Kriter için $D_{i}+R_{i}$ Ve $D_{i}-R_{i}$ Değerlerinin Hesaplanması

6. Adım: Etki Yönlü Dağılım Grafiğinin Oluşturulması Eşik değeri, uzmanlar tarafindan belirlenmektedir veya bunun mümkün olmadığı durumlarda Toplam İlişki
Matrisinin (T) ortalaması alınarak hesaplanmaktadır.

7. Adım: Ağırlıkların (w) Belirlenmesi

$\mathrm{w}_{\mathrm{i}}=\sqrt{\left[\left(\mathrm{D}_{\mathrm{I}}+\mathrm{R}_{\mathrm{I}}\right)\right]^{2}+\left[\left(\mathrm{D}_{\mathrm{I}}-\mathrm{R}_{\mathrm{I}}\right)\right]^{2}}$

8. Adım: Yüzde Ağırlık Değerlerinin $\left(\mathrm{W}_{\mathrm{i}}\right)$ Belirlenmesi [19]

$\mathrm{W}_{\mathrm{i}}=\frac{\mathrm{w}_{\mathrm{i}}}{\sum_{\mathrm{i}=1}^{\mathrm{n}} \mathrm{w}_{\mathrm{i}}}$

\subsection{ELECTRE Yöntemi}

ELECTRE (Elemination and Choice Translating Reality English) yöntemi ilk kez 1966 yılında Beneyoun tarafından ortaya atılmış bir çoklu karar verme yöntemidir. Yöntem, her bir değerlendirme faktörü için alternatif karar noktaları arasında ikili üstünlük kıyaslamalarına dayanır. Aynı zamanda bu yöntem öne geçme veya baskınlık ilişsisine dayanan bir yöntemdir, her bir ölçüt için bir verimlilik bir de önem ölçüsü tespit edilir [20]. ELECTRE yönteminde aşağıdaki adımlar izlenmektedir [21]:

1. Adım: Karar Matrisinin (A) Oluşturulması

$$
A_{i j}=\left[\begin{array}{ccc}
r_{11} & \cdots & r_{1 n} \\
\vdots & \ddots & \vdots \\
r_{m 1} & \cdots & r_{m n}
\end{array}\right]
$$

2. Adım: Normalize karar matrisi (X) oluşturulması

$$
x_{i j}=\frac{r_{i j}}{\sqrt{\sum_{i=1}^{n}\left(r_{i j}\right)^{2}}} \mathrm{i}=1 . . \mathrm{m} ; \mathrm{j}=1 . . \mathrm{n}
$$

3.Adım: Ağırlıklandırılmış normalize matris elde edilmesi

$$
\mathrm{V}_{\mathrm{ij}}=\mathrm{W}_{\mathrm{j}} \times \mathrm{X}_{\mathrm{ij}}
$$

V matrisi aşağıda gösterilmiştir:

$$
V_{i j}=\left[\begin{array}{ccc}
w_{1} * x_{11} & \cdots & w_{n} * x_{1 n} \\
\vdots & \ddots & \vdots \\
w_{1} * x_{m 1} & \cdots & w_{n} * x_{m n}
\end{array}\right]
$$

4. Adım: Uyum ve uyumsuzluk kümelerinin oluşturulması Uyum ve uyumsuzluk kümeleri oluşturulur. Her ikili alternatif kıyaslaması için kriterler iki ayrı kümeye ayrılır. $A_{p}$ ve $A_{q}(1,2, \ldots, m$ ve $p \neq q)$ uyum kümesinde $A_{p}$ alternatifi $\mathrm{A}_{\mathrm{q}}$ ' ya tercih edilmektedir.

$$
C(p, q)=\left\{j, V_{p j} \geq V_{q j}\right\}
$$

$A_{p}$ eğer $A_{q}$ 'dan daha kötü bir alternatif ise uyumsuzluk kümesi oluşturulur

$$
C(p, q)=\left\{j, V_{p j}<V_{q j}\right\}
$$


5. Adım: Uyum ve uyumsuzluk matrislerinin oluşturulması. Uyum matrisinin (C) oluşturulması için uyum setlerinden yararlanılır.

$$
C_{p q}=\sum_{j^{*}} w_{j}^{*}
$$

$j^{*}$ Uyum kümesi $C(p, q)$ ' da yer alan faktörlerdir.

Uyumsuzluk matrisinin (D) elemanları ise aşağıdaki formül yardımıyla hesaplanır:

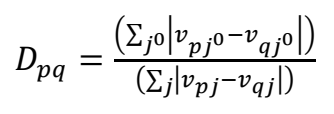

$j^{0}$ ise uyumsuzluk kümesi $\mathrm{D}(\mathrm{p}, \mathrm{q})$ 'da yer alan faktörledir

6. Adım: Üstünlük karşılaştırmalarının yapılması ve Uyum Üstünlük $\left(\mathrm{F}_{\mathrm{mxm}}\right)$ ve Uyumsuzluk Üstünlük $\left(\mathrm{G}_{\mathrm{mxm}}\right)$ Matrislerinin Oluşturulması.

$\mathrm{C}$ ve $\mathrm{D}$ değerlerinin ortalamaları olan $\bar{C}$ ve $\bar{D}$ değerleri aşağıdaki formüller ile hesaplanır. Eğer $C_{p q} \geq \bar{C}$ ve $D_{p q} \leq$ $\bar{D}$ ise $A p \rightarrow A q$ 'dır. Yani $p$. Birim ve $q$. birime göre üstündür.

$$
\begin{aligned}
& \bar{C}=\frac{1}{m(m-1)} \sum_{p=1}^{m} \sum_{q=1}^{m} C_{p q} \\
& \bar{D}=\frac{1}{m(m-1)} \sum_{p=1}^{m} \sum_{q=1}^{m} D_{p q}
\end{aligned}
$$

7. Adım: Toplam Baskınlık Matrisinin (E) Oluşturulması. Toplam Baskınlık Matrisinin (E) elemanları $\left(\mathrm{E}_{\mathrm{pq}}\right), \mathrm{F}_{\mathrm{pq}}$ ve $\mathrm{G}_{\mathrm{pq}}$ elemanlarının karşılıklı çarpımına eşittir.

8.Adım: Karar Noktalarının Önem Sırasının Belirlenmesi

\subsection{TOPSİS Yöntemi}

Çok kriterli karar verme yöntemlerinden bir tanesi olan Topsis yöntemi, nitel bir çevrim yapılmaksızın, direkt veri üzerinde uygulanabilmektedir (Technique For Order Preference By Similarity To An Ideal Solution (Topsis) yöntemi (1981) Hwang ve Yoon referansı ile Chen ve Hwang tarafindan sunulmuştur.

Topsis yöntemi ideal çözüme en yakın uzaklıkta ve negatif ideal çözüme en uzak bir çözüm belirler fakat yöntem bu uzaklıkların göreceli önemini dikkate almaz. Uzlaşılan çözüm, ideal çözümden en kısa öklit mesafesinde ve negatif ideal çözümden en uzak öklit mesafesinde tercih edilen çözüm olarak kabul edilebilir [22].

TOPSİS yönteminin aşamaları aşağıdaki şekilde ifade edilebilir [23].

1. Adım: Karar Matrisinin Oluşturulması. Tablo 5'de karar matrisinin yapısı gösterilmektedir.
Tablo 5. Örnek Bir Karar Matrisi

\begin{tabular}{|c|c|c|c|}
\hline \multirow{2}{*}{ ALTERNATIFLER } & \multicolumn{3}{|c|}{ ÖZELLIKLER } \\
\cline { 2 - 4 } & $\boldsymbol{y}_{\mathbf{1}}$ & $\boldsymbol{y}_{\mathbf{2}}$ & $\boldsymbol{y}_{\mathbf{3}}$ \\
\hline $\boldsymbol{a}_{\mathbf{1}}$ & $y_{11}$ & $y_{12}$ & $y_{1 k}$ \\
\hline $\boldsymbol{a}_{\mathbf{2}}$ & $y_{21}$ & $y_{22}$ & $y_{2 k}$ \\
\hline$\ldots$ & $\ldots$ & $\ldots$ & $\ldots$ \\
\hline$\ldots$ & $\ldots$ & $\ldots$ & $\ldots$ \\
\hline $\boldsymbol{a}_{\boldsymbol{n}}$ & $y_{n 1}$ & $y_{n 2}$ & $y_{n k}$ \\
\hline
\end{tabular}

2. Adım: Normalize Karar Matrisinin Oluşturulması.

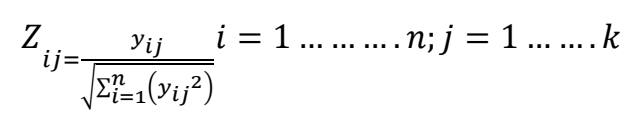

3. Adım: Ağırlıklandırılmış Normalize Karar Matrisinin Oluşturulması.

$$
X_{i j}=W_{i} * Z_{i j} i=1 \ldots \ldots \ldots n ; j=1 \ldots \ldots . k
$$

\section{(W her bir j kriterinin a $\breve{\mathrm{g}} \iota r l \mathrm{l} \breve{\mathrm{g}} \iota)$}

4. Adım: $m^{*}$ ve $m^{-}$İdeal Noktalarının Tanımlanması.

$$
\begin{aligned}
& m^{*}=\left[x_{1}^{*}, x_{2}^{*}, \ldots \ldots \ldots x_{k}^{*}\right] \text { (maksimum değerler) } \\
& m^{-}=\left[x_{1}^{-}, x_{2}^{-}, \ldots \ldots \ldots x_{n}^{-}\right] \text {(minimum değerler) }
\end{aligned}
$$

5. Adım: Maksimum İdeal Noktaya Olan Uzaklığın Hesaplanması $\left(S_{i}^{*}\right)$

$$
S_{i}^{*}=\sqrt{\sum_{j=1}^{k}\left(x_{i j}-x_{j}^{*}\right)} i=1 \ldots \ldots \ldots n
$$

6. Adım: Minimum Noktaya Olan Uzaklığın Hesaplanması $\left(S_{i}^{-}\right)$

$$
S_{i}^{-}=\sqrt{\sum_{j=1}^{k}\left(x_{i j}-x_{j}^{-}\right)} i=1 \ldots \ldots \ldots n
$$

7. Adım: Her bir alternatifin Göreceli Sıralamasının Oluşturulması Ve Puanlarının Hesaplanması $\left(C_{i}^{*}\right)$

$$
C_{i}^{*}=\frac{s_{i}^{-}}{S_{i}^{-}+S_{i}^{*}} \quad 0 \leq C_{i}^{*} \leq 1 i=1 \ldots \ldots \ldots n
$$

\section{UYGULAMA}

Çalışmada haddeleme esnasında ortaya çıkan hata türleri HTEA ile belirlenmiştir. Haddehanede kalitesiz, ikinci kaliteye düşen ürünler araştırılmıştır. Hatalı ürünlerin hangi sebeplerle oluştuğu uzman görüşleri ile belirlenmiştir. Tespit Edilen hatalar, işletmenin karşısına sürekli çıkarak üretimi yavaşlatmasının yanı sıra sistemin tamamen durmasına, yüksek kayıplara sebebiyet olan müşteri 
memnuniyetsizliğine kadar gitmektedir. Tespit edilen hatalar, Tablo 6'da gösterildiğ gibidir.

\subsection{HTEA RÖS Hesabı}

İşletmedeki geçmiş verilerden elde edilen bilgiler 1şığında uzman görüşleri ile bu hataların Ortaya Çıkma, Şiddet ve Saptama değerleri belirlenmiş ve Formül 1 kullanılarak RÖS değerleri hesaplanmıştır. Klasik HTEA RÖS değerleri baz alınarak oluşan hata sıralaması Tablo 7 ve Şekil 3'de verilmiştir.
İşletmede 15 hata türü tespit edilmiştir. 15 hata türünün önceliklendirilmesi için üç ana kriter olarak; Olasılık, Şiddet ve Saptama değerleri bulunmaktadır. İlk adım olarak kriterler için, işletmedeki uzman görüşleri alınarak Dematel Sözel Değerlendirme tablosu (Tablo 8) ve buna bağlı olarak Direk İlişki Matrisi(A) (Tablo 9) oluşturulmuştur. Yöntemin bölüm 2.2'de verilen adımları uygulanarak gerekli hesaplamaların yapılması neticesinde; Tablo 10'da Normalleştirilmiş Direk İlişki Matrisi(M), Tablo 11'de ise Toplam İlişki Matrisi (T) değerleri sunulmuştur.

Tablo 6. Hata Türlerinin Klasik HTEA ile Değerlendirilmesi

\begin{tabular}{|c|l|c|c|c|c|}
\hline Hata No & \multicolumn{1}{|c|}{ Hata Türü } & O & Ş & S & RÖS \\
\hline$\underline{\mathbf{1}}$ & $\begin{array}{l}\text { Hammadde olarak kullanılan kütükteki Kükürt oranının yüksek olması ile } \\
\text { haddeleme esnasında sıcak kısalık oluşması ile kaynaklanan şekil bozuklukları }\end{array}$ & 4 & 3 & 2 & $\mathbf{2 4}$ \\
\hline$\underline{\mathbf{2}}$ & $\begin{array}{l}\text { Hammadde olarak kullanılan kütükteki Fosfor oranının yüksek olması ile } \\
\text { haddeleme esnasında soğuk kısalık oluşması ile kaynaklanan şekil bozuklukları }\end{array}$ & 2 & 7 & 7 & $\mathbf{9 8}$ \\
\hline$\underline{\mathbf{3}}$ & Üretilen kare demirlerinde karelikte sapma görülmesi & 8 & 9 & 10 & $\mathbf{7 2 0}$ \\
\hline$\underline{\mathbf{4}}$ & Üretilen Yuvarlak demirlerde ovalite sapması oluşması & 8 & 7 & 9 & $\mathbf{5 0 4}$ \\
\hline$\underline{\mathbf{5}}$ & $\begin{array}{l}\text { Demirin kullanım ömrünü uzatılması için kullanılan sıcak çinko havuzunda çıkan } \\
\text { üründe gaz boşluğunun bulunması }\end{array}$ & 9 & 7 & 3 & $\mathbf{1 8 9}$ \\
\hline$\underline{\mathbf{6}}$ & Ürünlerde hadde eziği oluşumu & 5 & 8 & 4 & $\mathbf{1 6 0}$ \\
\hline$\underline{\mathbf{9}}$ & Uç kırı̆̆ının oluşumu & 4 & 9 & 6 & $\mathbf{2 1 6}$ \\
\hline$\underline{\mathbf{9}}$ & Kilcal çatlak oluşumu & 7 & 3 & 10 & $\mathbf{2 1 0}$ \\
\hline$\underline{\mathbf{1 0}}$ & Üretilen demirlerin doğrusallıklarının standartlara uymama durumu & 9 & 5 & 7 & $\mathbf{3 1 5}$ \\
\hline$\underline{\mathbf{1 1}}$ & $\begin{array}{l}\text { Cu ve Sn bileşimininde öngörülen sinır değerlerinden fazla olması durumunda } \\
\text { yüzey yırtılmalarının oluşması }\end{array}$ & 8 & 6 & 8 & $\mathbf{3 8 4}$ \\
\hline$\underline{\mathbf{1 2}}$ & Çapak yapışması & 4 & 5 & 5 & $\mathbf{1 0 0}$ \\
\hline$\underline{\mathbf{1 4}}$ & Paso patlağı oluşumu & 5 & 6 & 7 & $\mathbf{2 1 0}$ \\
\hline$\underline{\mathbf{1 5}}$ & Diş yüzeyde tav izi oluşumu & 6 & 7 & 6 & $\mathbf{2 5 2}$ \\
\hline & Tufal oluşumu & 7 & 8 & 2 & $\mathbf{1 1 2}$ \\
\hline & Gözenek oluşumu & 6 & 7 & 8 & $\mathbf{3 3 6}$ \\
\hline
\end{tabular}

Tablo 7. HTEA RÖS Siralı Tablosu

\begin{tabular}{|l|c|c|c|c|c|c|c|c|c|c|c|c|c|c|c|}
\hline SIra No & 1 & 2 & 3 & 4 & 5 & 6 & 7 & 8 & 9 & 10 & 11 & 12 & 13 & 14 & 15 \\
\hline Hata No & $\underline{\mathbf{3}}$ & $\underline{\mathbf{4}}$ & $\underline{\mathbf{1 0}}$ & $\underline{\mathbf{1 5}}$ & $\underline{\mathbf{9}}$ & $\underline{\mathbf{1 3}}$ & $\underline{\mathbf{7}}$ & $\underline{\mathbf{8}}$ & $\underline{\mathbf{1 2}}$ & $\underline{\mathbf{5}}$ & $\underline{\mathbf{6}}$ & $\underline{\mathbf{1 4}}$ & $\underline{\mathbf{1 1}}$ & $\underline{\mathbf{2}}$ & $\underline{\mathbf{1}}$ \\
\hline RÖS & 720 & 504 & 384 & 336 & 315 & 252 & 216 & 210 & 210 & 189 & 160 & 112 & 100 & 98 & 24 \\
\hline
\end{tabular}

Şekil 3. HTEA ile Hataların Öncelik Sıralaması

\subsection{DEMATEL Kriter Ağırlıklarının Belirlenmesi}

Hata türleri ve etkileri analiz sonuçlarının çok kriterli karar verme tekniklerinden olan TOPSIS ve ELECTRE yöntemleri ile değerlendirilip öncelikli hataların belirlenmesi amaçlandığından TOPSİS ve ELECTRE metotlarında kullanılacak ağırlık değerleri; Ortaya Çıkma, Şiddet ve Saptama değişkenleri için DEMATEL yöntemi kullanılarak belirlenmiştir.
Tablo 8. Sözel Değerlendirme Matrisi

\begin{tabular}{|l|c|c|c|}
\hline Değerlendirme & $\begin{array}{c}\text { Ortaya } \\
\text { Çıkma }\end{array}$ & Şiddet & Saptama \\
\hline Ortaya Çıkma & - & $\begin{array}{c}\text { Orta } \\
\text { Etki }\end{array}$ & $\begin{array}{c}\text { Çok Yüksek } \\
\text { Etki }\end{array}$ \\
\hline Şiddet & $\begin{array}{c}\text { Yüksek } \\
\text { Etki }\end{array}$ & - & $\begin{array}{c}\text { Çok Yüksek } \\
\text { Etki }\end{array}$ \\
\hline Saptama & $\begin{array}{c}\text { Yüksek } \\
\text { Etki }\end{array}$ & $\begin{array}{c}\text { Orta } \\
\text { Etki }\end{array}$ & - \\
\hline
\end{tabular}


Tablo 9. Direk İlişki Matrisi(A)

\begin{tabular}{|l|c|c|c|c|}
\hline & $\begin{array}{c}\text { Ortaya } \\
\text { Çıkma }\end{array}$ & Şiddet & Saptama & Toplam \\
\hline $\begin{array}{l}\text { Ortaya } \\
\text { Çıkma }\end{array}$ & - & 2 & 4 & 6 \\
\hline Şiddet & 3 & - & 4 & 7 \\
\hline Saptama & 3 & 2 & - & 5 \\
\hline Total & 6 & 4 & 8 & Max=8 \\
\hline
\end{tabular}

Tablo 10. Normalleştirilmiş Direk İlişki Matrisi(M)

\begin{tabular}{|l|c|c|c|}
\hline M Matrisi & $\begin{array}{c}\text { Ortaya } \\
\text { Çıkma }\end{array}$ & Şiddet & Saptama \\
\hline $\begin{array}{l}\text { Ortaya } \\
\text { Çıkma }\end{array}$ & 0 & 0,25 & 0,5 \\
\hline Şiddet & 0,375 & 0 & 0,5 \\
\hline Saptama & 0,375 & 0,25 & 0 \\
\hline
\end{tabular}

T Matrisinin; satır toplamları $D_{i}$ değerini verirken, sütün toplamları $R_{i}$ değerini verir. $D_{i}$ ve $R_{i}$ kriterler arası ilişkiyi gösteren en yüksek $\mathrm{D}+\mathrm{R}$ değerine sahip "Saptama" kriterinin, diğer kriterler ile daha çok ilişkide olduğunu göstermiştir. Kriter ağırlık değerleri Formül-8 temel alınarak hesaplanmış ve Tablo 12'de gösterilmiştir.

Tablo 11. Toplam İlişki Matrisi (T)

\begin{tabular}{|l|c|c|c|c|}
\hline & $\begin{array}{l}\text { Ortaya } \\
\text { Çıkma }\end{array}$ & Şiddet & Saptama & Toplam \\
\hline $\begin{array}{l}\text { Ortaya } \\
\text { Çıkma }\end{array}$ & 0,750 & 0,750 & 1,250 & 2,750 \\
\hline Şiddet & 1,125 & 0,625 & 1,375 & 3,125 \\
\hline Saptama & 0,938 & 0,688 & 0,813 & 2,438 \\
\hline $\begin{array}{l}\text { Toplam } \\
\left(\mathbf{R}_{\mathbf{i}}\right)\end{array}$ & 2,813 & 2,063 & 3,438 & \\
\hline
\end{tabular}

Çıkan sonuçlar doğrultusunda kriter ağırlıkları; Olasılık için 0.331 , Şiddet için 0.315 ve Saptama için ise 0.354 olarak Dematel yöntemi ile tespit edilmiştir (Tablo 12).

\subsection{DEMATEL-ELECTRE Hata Siralaması}

Sistematik bir yaklaşım olan Çok Kiterli Karar Verme yöntemlerinden ELECTRE metodu ile hataların öncelik sıralaması yapılmıştır. ELECTRE metodunda kullanılacak kriter ağırlıkları Dematel yöntemi kullanılarak verilen ağırlıklardır. Amaç ilk adımda acil hangi hata türünün üzerine yoğunlaşılsın sorusuna cevap aramaktır. Kriterlerimiz, hata türleri ve etkileri analizi kriterlerinden olan; Ortaya Çıkma, Şiddet ve Saptama değerleridir (Tablo 13).

ELECTRE metodunun ilk adımı olan karar matrisi normalleştirilerek $\mathrm{X}_{\mathrm{ij}}$ değerleri bulunur. Bunun için normalleştirme formülü olarak Formül-10 kullanılmıştır (Tablo 14).

3.adımda normalize değerler ağırlıklarla çapılarak ağırlıklandırılmış normalize matris elde edilir (Tablo 15).

ELECTRE'nin sonraki adımlarında ise; Uyum ve uyumsuzluk kümelerinin oluşturulması sağlanmıştır. DEMATEL kriter ağırlıkları kullanılarak oluşturulan uyum matrisindeki veriler Formül-16 kullanılarak bulunmuş uyum eşiği değeri 0,550 ile karşılaştırılarak, uyum üstünlük matrisi oluşturulmuştur (Tablo 16). Uyum setlerinin satır ve sütun kısımlarındaki sayılar hata türlerini temsil etmektedir.

DEMATEL kriter ağırlıkları kullanılarak oluşturulan uyumsuzluk matrisindeki değerler, Formül-17 kullanılarak bulunmuş uyumsuzluk eşiği değeri 0,306 ile karşılaştırılarak uyumsuzluk üstünlük matrisi oluşturulur (Tablo 17).

DEMATEL kriter ağırlıkları kullanılarak oluşturulan uyum üstünlük matrisi ile uyumsuzluk üstünlük matrisleri arasındaki baskınlık incelenerek toplam baskınlık matrisi oluşturulmuştur (Tablo 18).

Tablo 12. DEMATEL Kriter Ağırlıkları Hesaplaması

\begin{tabular}{|l|r|r|r|r|r|r|}
\hline & \multicolumn{1}{|c|}{$\left.\mathbf{( D}_{\mathbf{i}}\right)$} & \multicolumn{1}{c|}{$\left(\mathbf{R}_{\mathbf{i}}\right)$} & $\mathbf{( D + R})$ & \multicolumn{1}{c|}{$\mathbf{( D - R )}$} & \multicolumn{1}{c|}{$\mathbf{W}_{\mathbf{i}}$} & Normalleştirilmiş W $_{\mathbf{i}}$ \\
\hline Ort. Çıkma (O) & 2,750 & 2,813 & 5,563 & $-0,063$ & 5,563 & $\mathbf{0 , 3 3 1}$ \\
\hline Şiddet (S) & 3,125 & 2,063 & 5,188 & 1,063 & 5,295 & $\mathbf{0 , 3 1 5}$ \\
\hline Saptama(D) & 2,438 & 3,438 & $\mathbf{5 , 8 7 5}$ & $-1,000$ & 5,959 & $\mathbf{0 , 3 5 4}$ \\
\hline
\end{tabular}

Tablo 13. ELECTRE Karar Matrisi

\begin{tabular}{|c|c|c|c|c|c|c|c|c|c|c|c|c|c|c|c|c|}
\hline & & \multicolumn{15}{|c|}{ Hata No } \\
\hline & & $\underline{1}$ & $\underline{2}$ & $\underline{3}$ & $\underline{4}$ & $\underline{5}$ & $\underline{6}$ & $\underline{7}$ & $\underline{8}$ & $\underline{9}$ & $\underline{10}$ & $\underline{11}$ & $\underline{12}$ & $\underline{13}$ & $\underline{14}$ & $\underline{15}$ \\
\hline \multirow{3}{*}{ Kriterler } & Ort. Çıkma (O) & 4 & 2 & 8 & 8 & 9 & 5 & 4 & 7 & 9 & 8 & 4 & 5 & 6 & 7 & 6 \\
\hline & Şiddet $(S)$ & 3 & 7 & 9 & 7 & 7 & 8 & 9 & 3 & 5 & 6 & 5 & 6 & 7 & 8 & 7 \\
\hline & $\operatorname{Saptama}(D)$ & 2 & 7 & 10 & 9 & 3 & 4 & 6 & 10 & 7 & 8 & 5 & 7 & 6 & 2 & 8 \\
\hline
\end{tabular}


Tablo 14. NormalleştirilmişKarar Matrisi

\begin{tabular}{|c|c|c|c|c|c|c|c|c|c|c|}
\hline \multirow{2}{*}{$\boldsymbol{X}_{i j}$} & \multicolumn{9}{|c|}{ Hata No } & \multicolumn{1}{c|}{ DEMATEL $\boldsymbol{W}_{\boldsymbol{i}}$} \\
\cline { 2 - 12 } & $\underline{\mathbf{1}}$ & $\underline{\mathbf{2}}$ & $\underline{\mathbf{3}}$ & $\underline{\mathbf{4}}$ & $\underline{\mathbf{5}}$ & $\mathbf{. . . .}$ & $\underline{\mathbf{1 3}}$ & $\underline{\mathbf{1 4}}$ & $\underline{\mathbf{1 5}}$ & \\
\hline $\mathbf{O}$ & 0,160 & 0,080 & 0,320 & 0,320 & 0,360 &.. & 0,240 & 0,280 & 0,240 & $\mathbf{0 , 3 3 1}$ \\
\hline $\mathbf{S}$ & 0,115 & 0,269 & 0,346 & 0,269 & 0,269 &.. & 0,269 & 0,308 & 0,269 & $\mathbf{0 , 3 1 5}$ \\
\hline $\mathbf{D}$ & 0,076 & 0,267 & 0,382 & 0,344 & 0,115 &.. & 0,229 & 0,076 & 0,305 & $\mathbf{0 , 3 5 4}$ \\
\hline
\end{tabular}

Tablo 15. Ağırlıklandırılmış Normalize Karar Matrisi

\begin{tabular}{|c|c|c|c|c|c|c|c|c|c|c|c|c|c|c|c|}
\hline \multirow{2}{*}{$\mathbf{v}_{\mathbf{i j}}=\mathbf{W}_{\mathbf{j}} \mathbf{x} \mathbf{X}_{\mathbf{i j}}$} & \multicolumn{15}{|c|}{ Hata No } \\
\hline & $\underline{1}$ & $\underline{2}$ & $\underline{3}$ & $\underline{4}$ & $\underline{5}$ & $\underline{6}$ & $\underline{7}$ & $\underline{8}$ & $\underline{9}$ & $\underline{10}$ & $\underline{11}$ & $\underline{12}$ & $\underline{13}$ & $\underline{14}$ & $\underline{15}$ \\
\hline O.Çıkma(O) & 0,053 & 0,026 & 0,106 & 0,106 & 0,119 & 0,066 & 0,053 & 0,093 & 0,119 & 0,106 & 0,053 & 0,066 & 0,079 & 0,093 & 0,079 \\
\hline Şiddet (S) & 0,036 & 0,085 & 0,109 & 0,085 & 0,085 & 0,097 & 0,109 & 0,036 & 0,061 & 0,073 & 0,061 & 0,073 & 0,085 & 0,097 & 0,085 \\
\hline $\operatorname{Saptama}(D)$ & 0,027 & 0,095 & 0,135 & 0,122 & 0,041 & 0,054 & 0,081 & 0,135 & 0,095 & 0,108 & 0,068 & 0,095 & 0,081 & 0,027 & 0,108 \\
\hline
\end{tabular}

Tablo 16. DEMATEL-ELECTRE Uyum Üstünlük Matrisi

\begin{tabular}{|c|c|c|c|c|c|c|c|c|c|c|c|c|c|c|c|}
\hline Hata No: & $\underline{1}$ & $\underline{2}$ & $\underline{3}$ & $\underline{4}$ & $\underline{5}$ & $\underline{6}$ & $\underline{7}$ & $\underline{8}$ & $\underline{9}$ & $\underline{10}$ & $\underline{11}$ & $\underline{12}$ & $\underline{13}$ & $\underline{14}$ & $\underline{15}$ \\
\hline$\underline{1}$ & & 0 & 0 & 0 & 0 & 0 & 0 & 0 & 0 & 0 & 0 & 0 & 0 & 0 & 0 \\
\hline$\underline{2}$ & 1 & & 0 & 0 & 1 & 0 & 0 & 0 & 1 & 0 & 1 & 1 & 1 & 0 & 0 \\
\hline$\underline{3}$ & 1 & 1 & & 1 & 1 & 1 & 1 & 1 & 1 & 1 & 1 & 1 & 1 & 1 & 1 \\
\hline$\underline{4}$ & 1 & 1 & 0 & & 1 & 1 & 1 & 1 & 1 & 1 & 1 & 1 & 1 & 1 & 1 \\
\hline$\underline{5}$ & 1 & 1 & 0 & 1 & & 0 & 0 & 1 & 1 & 1 & 1 & 1 & 1 & 1 & 1 \\
\hline$\underline{6}$ & 1 & 1 & 0 & 0 & 1 & & 0 & 0 & 0 & 0 & 1 & 1 & 0 & 1 & 0 \\
\hline$\underline{7}$ & 1 & 1 & 0 & 0 & 1 & 1 & & 0 & 0 & 0 & 1 & 0 & 1 & 1 & 0 \\
\hline$\underline{8}$ & 1 & 1 & 0 & 0 & 0 & 1 & 1 & & 0 & 0 & 1 & 1 & 1 & 1 & 1 \\
\hline$\underline{9}$ & 1 & 1 & 0 & 0 & 1 & 1 & 1 & 1 & & 0 & 1 & 1 & 1 & 1 & 0 \\
\hline$\underline{10}$ & 1 & 1 & 0 & 0 & 0 & 1 & 1 & 1 & 1 & & 1 & 1 & 1 & 1 & 1 \\
\hline$\underline{11}$ & 1 & 0 & 0 & 0 & 0 & 0 & 0 & 0 & 0 & 0 & & 0 & 0 & 0 & 0 \\
\hline$\underline{12}$ & 1 & 1 & 0 & 0 & 0 & 1 & 1 & 0 & 1 & 0 & 1 & & 0 & 0 & 0 \\
\hline$\underline{13}$ & 1 & 1 & 0 & 0 & 1 & 1 & 1 & 0 & 0 & 0 & 1 & 1 & & 0 & 1 \\
\hline$\underline{14}$ & 1 & 1 & 0 & 0 & 0 & 1 & 0 & 1 & 0 & 0 & 1 & 1 & 1 & & 1 \\
\hline$\underline{15}$ & 1 & 1 & 0 & 0 & 1 & 1 & 1 & 0 & 1 & 1 & 1 & 1 & 1 & 0 & \\
\hline
\end{tabular}

Tabloya bakıldığında, ilk sıradaki hata 3. Hata olmuştur. Daha sonrasında 3. Hatayı 4, 10 ve 15 . hatalar takip etmektedir. Hataların öncelik sırası Tablo 19 ve Şekil 4'deki gibidir.

Tablo 17. DEMATEL-ELECTRE Uyumsuzluk üstünlük matrisi

\begin{tabular}{|c|c|c|c|c|c|c|c|c|c|c|c|c|c|c|c|}
\hline Hata No: & $\underline{\mathbf{1}}$ & $\underline{\mathbf{2}}$ & $\underline{\mathbf{3}}$ & $\underline{\mathbf{4}}$ & $\underline{\mathbf{5}}$ & $\underline{\mathbf{6}}$ & $\underline{\mathbf{Z}}$ & $\underline{\mathbf{8}}$ & $\underline{\mathbf{9}}$ & $\underline{\mathbf{1}}$ & $\underline{\mathbf{1}}$ & $\underline{\mathbf{1 2}}$ & $\underline{\mathbf{1 3}}$ & $\underline{\mathbf{1 4}}$ & $\underline{\mathbf{1 5}}$ \\
\hline$\underline{\boldsymbol{1}}$ & & 0 & 0 & 0 & 0 & 0 & 0 & 0 & 0 & 0 & 0 & 0 & 0 & 0 & 0 \\
\hline$\underline{\mathbf{2}}$ & 1 & & 0 & 0 & 0 & 0 & 1 & 0 & 0 & 0 & 1 & 0 & 0 & 0 & 0 \\
\hline$\underline{\mathbf{3}}$ & 1 & 1 & & 1 & 1 & 1 & 1 & 1 & 1 & 1 & 1 & 1 & 1 & 1 & 1 \\
\hline$\underline{\mathbf{4}}$ & 1 & 1 & 1 & & 1 & 1 & 1 & 1 & 1 & 1 & 1 & 1 & 1 & 1 & 1 \\
\hline$\underline{\mathbf{5}}$ & 1 & 0 & 0 & 0 & & 1 & 0 & 0 & 0 & 0 & 1 & 0 & 0 & 1 & 0 \\
\hline$\underline{\boldsymbol{\sigma}}$ & 1 & 0 & 0 & 0 & 0 & & 1 & 0 & 0 & 0 & 1 & 0 & 1 & 1 & 0 \\
\hline$\underline{\boldsymbol{Z}}$ & 1 & 1 & 0 & 0 & 0 & 1 & & 0 & 0 & 0 & 1 & 1 & 1 & 0 & 1 \\
\hline$\underline{\boldsymbol{g}}$ & 1 & 0 & 0 & 0 & 0 & 0 & 0 & & 1 & 0 & 1 & 0 & 0 & 0 & 0 \\
\hline
\end{tabular}




\begin{tabular}{|l|l|l|l|l|l|l|l|l|l|l|l|l|l|l|l|}
\hline$\underline{\boldsymbol{9}}$ & 1 & 1 & 0 & 1 & 1 & 0 & 0 & 0 & & 1 & 1 & 1 & 1 & 0 & 1 \\
\hline$\underline{\mathbf{1 0}}$ & 1 & 1 & 0 & 1 & 1 & 1 & 0 & 1 & 1 & & 1 & 1 & 1 & 1 & 1 \\
\hline$\underline{\mathbf{1 1}}$ & 1 & 1 & 0 & 0 & 0 & 0 & 0 & 0 & 0 & 0 & & 1 & 1 & 0 & 0 \\
\hline$\underline{\mathbf{1 2}}$ & 1 & 1 & 0 & 0 & 0 & 1 & 0 & 0 & 0 & 0 & 1 & & 1 & 1 & 1 \\
\hline$\underline{\mathbf{1 3}}$ & 1 & 1 & 0 & 0 & 0 & 1 & 1 & 0 & 0 & 1 & 1 & 1 & & 1 & 1 \\
\hline$\underline{\mathbf{1 4}}$ & 1 & 0 & 0 & 0 & 1 & 1 & 0 & 0 & 0 & 0 & 0 & 0 & 0 & & 0 \\
\hline$\underline{\mathbf{1 5}}$ & 1 & 1 & 1 & 1 & 0 & 1 & 1 & 1 & 0 & 1 & 1 & 1 & 1 & 1 & \\
\hline
\end{tabular}

Tablo 18. DEMATEL-ELECTRE Toplam Baskınlık Matrisi

\begin{tabular}{|c|c|c|c|c|c|c|c|c|c|c|c|c|c|c|c|c|}
\hline Hata No: & $\underline{1}$ & $\underline{2}$ & $\underline{3}$ & $\underline{4}$ & $\underline{5}$ & $\underline{6}$ & $\underline{7}$ & $\underline{8}$ & $\underline{9}$ & $\underline{10}$ & $\underline{11}$ & $\underline{12}$ & $\underline{13}$ & $\underline{14}$ & $\underline{15}$ & Toplam \\
\hline$\underline{1}$ & 0 & 0 & 0 & 0 & 0 & 0 & 0 & 0 & 0 & 0 & 0 & 0 & 0 & 0 & 0 & 0 \\
\hline$\underline{2}$ & 1 & 0 & 0 & 0 & 0 & 0 & 0 & 0 & 0 & 0 & 1 & 0 & 0 & 0 & 0 & 2 \\
\hline$\underline{3}$ & 1 & 1 & 0 & 1 & 1 & 1 & 1 & 1 & 1 & 1 & 1 & 1 & 1 & 1 & 1 & 14 \\
\hline$\underline{4}$ & 1 & 1 & 0 & 0 & 1 & 1 & 1 & 1 & 1 & 1 & 1 & 1 & 1 & 1 & 1 & 13 \\
\hline$\underline{5}$ & 1 & 0 & 0 & 0 & 0 & 0 & 0 & 0 & 0 & 0 & 1 & 0 & 0 & 1 & 0 & 3 \\
\hline$\underline{6}$ & 1 & 0 & 0 & 0 & 0 & 0 & 0 & 0 & 0 & 0 & 1 & 0 & 0 & 1 & 0 & 3 \\
\hline$\underline{7}$ & 1 & 1 & 0 & 0 & 0 & 1 & 0 & 0 & 0 & 0 & 1 & 0 & 1 & 0 & 0 & 5 \\
\hline$\underline{8}$ & 1 & 0 & 0 & 0 & 0 & 0 & 0 & 0 & 0 & 0 & 1 & 0 & 0 & 0 & 0 & 2 \\
\hline$\underline{9}$ & 1 & 1 & 0 & 0 & 1 & 0 & 0 & 0 & 0 & 0 & 1 & 1 & 1 & 0 & 0 & 6 \\
\hline$\underline{10}$ & 1 & 1 & 0 & 0 & 0 & 1 & 0 & 1 & 1 & 0 & 1 & 1 & 1 & 1 & 1 & 10 \\
\hline 11 & 1 & 0 & 0 & 0 & 0 & 0 & 0 & 0 & 0 & 0 & 0 & 0 & 0 & 0 & 0 & 1 \\
\hline$\underline{12}$ & 1 & 1 & 0 & 0 & 0 & 1 & 0 & 0 & 0 & 0 & 1 & 0 & 0 & 0 & 0 & 4 \\
\hline$\underline{13}$ & 1 & 1 & 0 & 0 & 0 & 1 & 1 & 0 & 0 & 0 & 1 & 1 & 0 & 0 & 1 & 7 \\
\hline$\underline{14}$ & 1 & 0 & 0 & 0 & 0 & 1 & 0 & 0 & 0 & 0 & 0 & 0 & 0 & 0 & 0 & 2 \\
\hline$\underline{15}$ & 1 & 1 & 0 & 0 & 0 & 1 & 1 & 0 & 0 & 1 & 1 & 1 & 1 & 0 & 0 & 8 \\
\hline
\end{tabular}

Tablo 19. DEMATEL Ağırlıkları Kullanılan ELECTRE Baskınlık Tablosu

\begin{tabular}{|c|c|c|c|c|c|c|c|c|c|c|c|c|c|c|c|}
\hline Sira No & 1 & 2 & 3 & 4 & 5 & 6 & 7 & 8 & 9 & 10 & 11 & 12 & 13 & 14 & 15 \\
\hline Hata No & $\underline{\mathbf{3}}$ & $\underline{\mathbf{4}}$ & $\underline{\mathbf{1 0}}$ & $\underline{\mathbf{1 5}}$ & $\underline{\mathbf{1 3}}$ & $\underline{\mathbf{9}}$ & $\underline{\mathbf{7}}$ & $\underline{\mathbf{1 2}}$ & $\underline{\mathbf{5}}$ & $\underline{\mathbf{6}}$ & $\underline{\mathbf{2}}$ & $\underline{\mathbf{8}}$ & $\underline{\mathbf{1 4}}$ & $\underline{\mathbf{1 1}}$ & $\underline{\mathbf{1}}$ \\
\hline Baskınlık Değeri & 14 & 13 & 10 & 8 & 7 & 6 & 5 & 4 & 3 & 3 & 2 & 2 & 2 & 1 & 0 \\
\hline
\end{tabular}

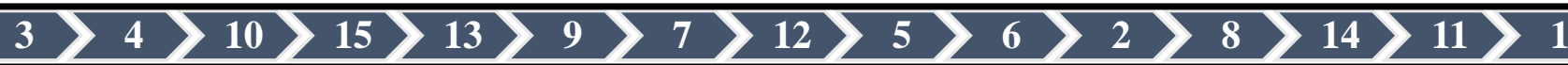

Şekil 4. DEMATEL-ELECTRE ile Hataların Öncelik Sıralaması

\subsection{DEMATEL-TOPSİS Hata Sıralaması}

Yöntemin ilk iki adımı ELECTRE yöntemi ile ortaktır. Aşağıda, TOPSİS yönteminin adımları sırasıyla gerçekleştirilmiştir. A matrisi karar verici tarafindan oluşturulan başlangıç matrisidir. Bu matris Tablo 20'deki gibidir. Normalize Karar Matrisi(Tablo 21), karar matrisinin elemanlarından yararlanarak Bölüm 2.4'de verilmiş olan Formül-18 kullanılarak hesaplanır. Normalize karar matrisinin her bir sütunundaki elemanlar ilgili kriter ağırlık değeri ile çarpılarak V matrisi oluşturulur. Ağırlıklı Normalize Karar Matrisi (V) Tablo 22 'de gösterilmiştir.
Formül-20 ve Formül-21 ile, ideal ve negatif ideal çözümler oluşturulur. Elde edilen karar noktalarına ilişskin

sapma değerleri ise, Formül-22 ve Formül-23 'den hesaplanarak, İdeal Ayrım ve Negatif İdeal Ayrım değerleri şeklinde Tablo 23'de gösterilmiştir. Hesaplanan ideal ve negatif ideal çözüm değerleri kullanılarak ideal çözüme göreli yakınlık değeri olan C değeri Formül-24 baz alınarak hesaplanmıştır. $\mathrm{C}$ değerleri büyükten küçüğe doğru sıralanarak çözüme en yakın değerler ilk sırada yer alır (Tablo 24).

İlk önceliklenen hata 3 . Hata olmuştur. Daha sonrasında 3. Hatayı 4, 10 ve 15. hatalar takip etmektedir. Hataların öncelik sıralaması şekil 5'deki gibidir.. 
Tablo 20. Karar Matrisi

\begin{tabular}{|c|c|c|c|c|c|c|c|c|c|c|c|c|c|c|c|c|}
\hline & \multicolumn{15}{|c|}{ Hata No } \\
\hline & & 1 & 2 & $\underline{3}$ & 4 & 5 & 6 & 7 & 8 & 9 & 10 & 11 & 12 & 13 & 14 & $\underline{15}$ \\
\hline \multirow{3}{*}{ Kriterler } & Ort. Çıkma (O) & 4 & 2 & 8 & $\overline{8}$ & 9 & 5 & 4 & 7 & 9 & 8 & $\overline{4}$ & 5 & 6 & 7 & $\overline{6}$ \\
\hline & Şiddet (S) & 3 & 7 & 9 & 7 & 7 & 8 & 9 & 3 & 5 & 6 & 5 & 6 & 7 & 8 & 7 \\
\hline & Saptama(D) & 2 & 7 & 10 & 9 & 3 & 4 & 6 & 10 & 7 & 8 & 5 & 7 & 6 & 2 & 8 \\
\hline
\end{tabular}

Tablo 21. Normalize Karar Matrisi Tablosu

\begin{tabular}{|c|c|c|c|c|c|c|c|c|c|c|c|c|c|c|c|c|}
\hline & \multicolumn{15}{|c|}{ Hata No } & \multirow[t]{2}{*}{$\begin{array}{c}\text { DEMATEL } \\
W_{i} \\
\end{array}$} \\
\hline & $\underline{1}$ & $\underline{2}$ & $\underline{3}$ & $\underline{4}$ & $\underline{5}$ & $\underline{6}$ & $\underline{7}$ & $\underline{8}$ & $\underline{9}$ & $\underline{10}$ & $\underline{11}$ & $\underline{12}$ & $\underline{13}$ & $\underline{14}$ & $\underline{15}$ & \\
\hline O. Çıkma(O) & 0,160 & 0,080 & 0,320 & 0,320 & 0,360 & 0,200 & 0,160 & 0,280 & 0,360 & 0,320 & 0,160 & 0,200 & 0,240 & 0,280 & 0,240 & 0,331 \\
\hline Şiddet (S) & 0,115 & 0,269 & 0,346 & 0,269 & 0,269 & 0,308 & 0,346 & 0,115 & 0,192 & 0,231 & 0,192 & 0,231 & 0,269 & 0,308 & 0,269 & 0,315 \\
\hline $\operatorname{Saptama(D)}$ & 0,076 & 0,267 & 0,382 & 0,344 & 0,115 & 0,153 & 0,229 & 0,382 & 0,267 & 0,305 & 0,191 & |0,267 & 0,229 & 0,076 & 0,305 & 0,354 \\
\hline
\end{tabular}

Tablo 22. DEMATEL Ağırlıkları Temel Alınarak Oluşturulan V Matrisi

\begin{tabular}{|l|c|c|c|c|c|c|c|c|c|c|c|c|c|c|c|}
\hline & \multicolumn{10}{|c|}{ Hata No } \\
\hline \multicolumn{1}{|c|}{ Kriterler } & $\underline{\mathbf{1}}$ & $\underline{\mathbf{2}}$ & $\underline{\mathbf{3}}$ & $\underline{\mathbf{4}}$ & $\underline{\mathbf{5}}$ & $\underline{\mathbf{6}}$ & $\underline{\mathbf{z}}$ & $\underline{\mathbf{8}}$ & $\underline{\mathbf{9}}$ & $\underline{\mathbf{1 0}}$ & $\underline{\mathbf{1 1}}$ & $\underline{\mathbf{1 2}}$ & $\underline{\mathbf{1 3}}$ & $\underline{\mathbf{1 4}}$ & $\underline{\mathbf{1 5}}$ \\
\hline O. Çıma(O) & 0,053 & 0,026 & 0,106 & 0,106 & 0,119 & 0,066 & 0,053 & 0,093 & 0,119 & 0,106 & 0,053 & 0,066 & 0,079 & 0,093 & 0,079 \\
\hline Şiddet (S) & 0,036 & 0,085 & 0,109 & 0,085 & 0,085 & 0,097 & 0,109 & 0,036 & 0,061 & 0,073 & 0,061 & 0,073 & 0,085 & 0,097 & 0,085 \\
\hline Saptama(D) & 0,027 & 0,095 & 0,135 & 0,122 & 0,041 & 0,054 & 0,081 & 0,135 & 0,095 & 0,108 & 0,068 & 0,095 & 0,081 & 0,027 & 0,108 \\
\hline
\end{tabular}

Tablo 23. DEMATEL Ağırlıklar Temel Alınarak Oluşturulan İdeal ve Negatif İdeal Çözümler Tablosu

\begin{tabular}{|c|c|c|c|c|c|c|c|c|c|c|c|c|c|c|c|}
\hline \multicolumn{16}{|c|}{ Hata No } \\
\hline & $\underline{1}$ & $\underline{2}$ & $\underline{3}$ & $\underline{4}$ & $\underline{5}$ & $\underline{6}$ & 7 & $\underline{8}$ & $\underline{9}$ & $\underline{10}$ & $\underline{11}$ & $\underline{12}$ & $\underline{13}$ & 14 & $\underline{15}$ \\
\hline$S_{i}^{*}$ & 0,146 & 0,104 & 0,013 & 0,031 & 0,098 & 0,098 & 0,085 & 0,077 & 0,063 & $0, \overline{047}$ & $0, \overline{106}$ & $\overline{0,076}$ & $0, \overline{071}$ & 0,112 & 0,054 \\
\hline$\left(S_{i}^{-}\right)$ & 0,026 & 0,083 & 0,153 & 0,133 & 0,105 & 0,077 & 0,094 & 0,127 & 0,117 & 0,119 & 0,054 & 0,086 & 0,090 & 0,090 & 0,108 \\
\hline
\end{tabular}

Tablo 24. DEMATEL A ğırlıkları Temel Alınarak Hesaplanan C Değerleri

\begin{tabular}{|c|c|c|c|c|c|c|c|c|c|c|c|c|c|c|c|}
\hline Sira No & 1 & 2 & 3 & 4 & 5 & 6 & 7 & 8 & 9 & 10 & 11 & 12 & 13 & 14 & 15 \\
\hline Hata No & $\underline{3}$ & $\underline{4}$ & $\underline{10}$ & $\underline{15}$ & 9 & $\underline{8}$ & $\underline{13}$ & $\underline{12}$ & $\underline{7}$ & $\underline{5}$ & $\underline{2}$ & $\underline{14}$ & $\underline{6}$ & $\underline{11}$ & 1 \\
\hline $\mathbf{C}$ & 0,92 & 0,812 & 0,716 & 0,668 & 0,65 & 0,621 & 0,557 & 0,532 & 0,525 & 0,519 & 0,445 & 0,444 & 0,442 & 0,338 & 0,153 \\
\hline
\end{tabular}

\section{$3>4>10>15>9>8>13>12>7>5>2>$}

\section{Şekil 5. DEMATEL-TOPSIS ile Hataların Öncelik Sıralaması}

\section{Yöntemlerin karşılaştırmalı değerlendirmesi}

İşletmeye en çok zararı olan hata türünün tespiti için; Klasik HTEA, DEMATEL-ELECTRE ve DEMATELTOPSİS yöntemleri kullanılmış ve çıkan sonuçlar karşılaştırmalı olarak verilmiştir. Hataların, üç farklı yöntem ile hata türlerinin işletmeye olan zararı ve aciliyetleri dikkate alınarak en çok olandan en az olana doğru sıralanması gerçekleştirilmiştir. Hataların kullanılan yöntemlerde kaçıncı sırada çıktıkları Şekil 6'da gösterilmiştir. Her üç yöntemde de, ilk önceliklenen hata 3 . Hata olmuştur. Daha sonrasında 3. Hatayı 4, 10 ve 15. hatalar takip etmektedir. 5.sıradan itibaren hataların siras1 yöntemlerde farklılık göstermektedir.
Ortaya çıkan sıralamalarda ilk hata olarak, üretilen kare demirlerde karelikte sapma görülmesi karşımıza çıkmaktadır. Karelikten sapma demek kare üretilen demirin merkezinden dış çevreye doğru olan uzaklığının demirin diğer bölümlerinde aynı olmaması durumudur. Yani üretilmek istenilen şekil standartlarına, üretilen demirin uymaması anlamına gelmektedir. Karelikten sapma tespit edilen ürünler, sapma oranlarına göre ikinci kalite ürün standartlarına düşmektedir. Eğer karelikten sapma oldukça yüksek ise demir direk olarak hurda sınıfina girmektedir. Gün içerisinde üretimden çıkan ürünlerde bu hata oldukça fazla oranda çıkıyor ise sistemin hadde kısmındaki merdanede bir sorun yaşanıyor demektir. Merdaneden kaynaklanan sorunlar bu hataya 
sebebiyet vermektedir. Bunun yanı sıra tav ocağından ayrılarak haddelemeye gelen ürün, bu süreçte soğuması gibi bir durumla karşılaşırsa haddeleme zorlaşacağından üretilen kare demirlerde karelikten sapma hatası yine oluşacaktır.

Üretilen Yuvarlak demirlerde ovalite sapması oluşması ikinci sıradaki hata türünü oluşturmaktadır. Yuvarlak demirlerde ovalite sapması oluşması demek yuvarlak demirin merkezinden çevresine olan uzaklığın, demir boyunca aynı olmaması demektir. Üretilen yuvarlak demirde, bu ovalite sapması belli bir standartta ise ürün sorun teşkil etmemektedir. Fakat standartlardan yüksek bir şekilde sapma oluşması, ürünün ikinci kalite olmasına; ovalite sapması oldukça yüksek ve düzeltilemez ise demirin hurda sınıfina girmesine sebep olur. $\mathrm{Bu}$ hata genellikle merdanelerden kaynaklıdır. Hadde merdanesinin yanlış yerleştirilmesi hadde merdanesinin dışındaki deformasyonlar ve haddede ürünün soğuması bu hatanın sebebiyetleri olarak gösterilebilir.

$\mathrm{Cu}$ ve Sn bileşiminin, öngörülen sınır değerlerinden fazla olması durumunda yüzey yırtılmalarının oluşması hatası ilk üç hatanın arasındadır. Bu hatanın, ürün prosese girmeden tespit edilmesi oldukça önemlidir. $\mathrm{Cu}$ ve $\mathrm{Sn}$ içeren demir kütüklerde numunenin ve örneklemin oldukça dikkatli alınması gerekir. Eğer tespit edilen değerler sınır değerinden yüksek ise ve ürün hala haddelemede bulunuyorsa sistemi durdurmaya kadar gidebilir. Sistem durdurulmayıp ürün üretilmiş ise hatalı ürün ikinci kaliteye veya hurda sinıfina girmektedir.

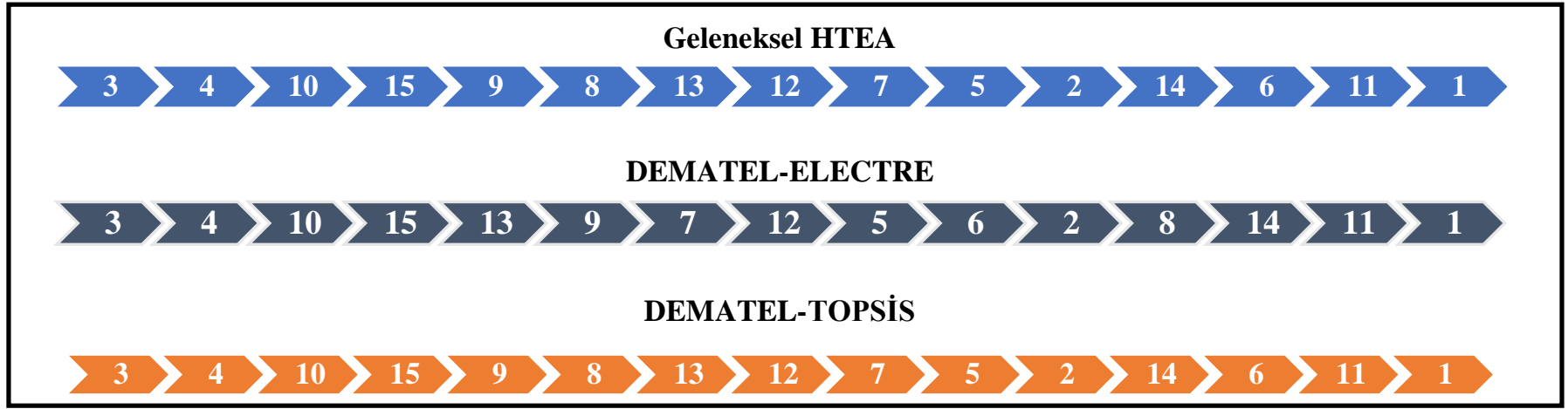

Şekil 6. Hata Türlerinin Karşılaştırmalı Sıralaması

\section{SONUÇ}

Klasik HTEA'nın basit ve hızlı uygulanabilen bir yapısı olmasına karşın, RÖS değerinin hesaplanma şekli hakkında giriş bölümünde incelenmiş olan pek çok kaynaktan da anlaşılabileceği gibi çeşitli eleştiriler bulunmaktadır. $\mathrm{Bu}$ eleştiriler neticesinde; Bulanık küme teorisi, Gri İlişkisel Analiz, ENTROPİ, VİKOR, AHP, TOPSİS gibi yöntemlerin müstakil ve/veya birlikte kullanılmaları ile farklı çalışmalar ortaya konulmuştur. Yapılan çalışmalarda, hataların tespiti ve etkilerinin azaltılması için, daha etkin ve karşılaştırmalı hata sıralamaları bulunması amaçlanmıştır.

Bu çalışmada, Klasik HTEA RÖS hesabı ve RÖS değeri parametreleri kullanılarak çok kriterli karar verme yöntemlerinden olan TOPSİS ve ELECTRE metotları ile hata türleri önceliklendirilmiştir. TOPSISS ve ELECTRE yöntemlerinde kullanılacak olan kriter ağırlıklarının belirlenmesi için de DEMATEL yöntemi tercih edilmiştir. Çok Kriterli Karar Verme yöntemlerinin üstünlüklerinden faydalanılarak, RÖS hesabının hata türlerini önceliklendirmede daha başarılı bir şekilde kullanılabilmesi sağlanmıştır. Hataların öncelik sıralamalarının bu üç yöntemle karşılaştırmalı olarak araştırılması işletmeye sonuçların çapraz kontrolünü yapma imkanı sağlamıştır.

İşletmeler bu yöntemlerden herhangi birini kullandıktan sonra elde ettiği önceliklendirme sırasına göre en yüksek hata türünden başlayarak iyileştirmeler yapabilir.
İyileştirmeler neticesinde aynı sıralama teknikleri tekrar tekrar uygulanarak düzeltilmiş FMEA RÖS değerleri hesaplanıp, dinamik bir hata önceliklendirme sistemine sahip olunabilir. $\mathrm{Bu}$ şekilde; işletme içi iyileştirme faaliyetlerinin sürekli hale getirilmesi ikinci kalite ürünlerin ve hurdaların azaltılmasını sağlayacak, bu da işletme verimliliğine ve karlılığına önemli katkılarda bulunacaktır. Gelecek çalışmalarda; HTEA'da tespit edilen hataların önceliklendirilmesi için diğer çok kriterli karar verme yöntemlerinden de faydalanılması düşünülebilir.

\section{KAYNAKÇA}

[1] S. H. Teng,S. Y. Ho, Failure mode and effects analysis: An integrated approach for product design and process control, International Journal of Quality and Reliability Management, 1996, 22,23.

[2] G.Aran, Kalite İyileştirme Sürecinde Hata Türü Etkileri Analizi (FMEA) ve Bir Uygulama, Yüksek Lisans Tezi, Gaziosmanpaşa Üniversitesi, Sosyal Bilimler Enstitüsü, Tokat, 2006, 189162.

[3] K. M. Tay, C. P. Lim, Fuzzy FMEA with a Guide Rules Reduction System for Priorization of Failures, International Journal of Quality \& Reliability Management, Vol: 23, 2006, No:8 (1047-1066)

[4]K. Taşan, Bir Risk Değerlendirme ve Güvenilirlik Metodu Olarak Hata Türü ve Etkileri Analizi (HTEA) Yöntemi: Bir Otomotiv Yan Sanayi İşletmesinde 
Uygulanmas1, Yüksek Lisans Tezi, Dokuz Eylül Üniversitesi, Sosyal Bilimler Enstitüsü, İzmir, 2006.

[5]H. C. Liu, L. Liu, N. Liu, L.X. Mao, Risk Evaluation in Failure Mode And Effects Analysis with extended VIKORMethod Under Fuzzy Environment, Expert Systems with Applications, Volume 39, 2012, Pages 12926-12934

[6]A. C. Kutlu, M. Ekmekcioğlu, "Fuzzy Failure Modes And Effects Analysis By Using Fuzzy TOPSIS-Based Fuzzy AHP”, Expert Systems with Applications 39, 2012, 61-67

[7]H. C. Liu, L. Liu, N. Liu, Risk Evaluation Approaches in Failure Mode And Effects Analysis: A Literature Review, Expert Systems with Applications, Volume 40, Issue 2, 1 February 2013, Pages 828-838

[8] Y. C. Chen, W. F. Wu, Constructing an Effective Prevention Mechanism for MSW Lifecycle Using Failure Mode and Effects Analysis, Waste Management, 46, 2015 646-652

[9]H. C. Liua, J. X. You, X. Y. You, M. M. Shan, A Novel Approach for Failure Mode And Effects Analysis Using Combination Weighting and Fuzzy VIKOR method, Applied Soft Computing, Volume 28, 2015, 579-588

[10] Q. Zhou, V. V. Thai, Fuzzy and Grey Theories in Failure Mode And Effect Analysis for Tanker Equipment Failure Prediction, Safety Science 83, 2016, 74-79

[11] H. S. Tooranloo, A. S. Ayatollah, A Model for Failure Mode And Effects Analysis Based on Intuitionistic Fuzzy Approach, Applied Soft Computing 49, 2016, 238-247

[12]M. Yazdi, S. Daneshvar, H. Setareh, An Extension to Fuzzy Developed Failure Mode and Effects Analysis (FDFMEA) Application for Aircraft Landing System, Safety Science 98, 2017, 113-123

[13] W. Jiang, C. Xie, M. Zhuang, Y. Tang, Failure Mode and Effects Analysis Based on a Novel Fuzzy Evidential Method", Applied Soft Computing 57, 2017, 672-683

[14]Y. Taş, K. Koç, The Application of the Failure Mode Effects Analysis to Furniture Industries". İstanbul Aydın
Üniversitesi Dergisi 2, 2010, 150-178

[15] D. Durhan, Hata Türü Ve Etkileri Analizi (Fmea) Ve Bir Uygulama, Yüksek Lisans Tezi, Gazi Üniversitesi, Fen Bilimleri Enstitüsü, Ankara, 2006.

[16] D. S. Chang, Sun, K. L. P. Sun, "Applying DEA to Enhance Assessment Capability of FMEA, International Journal of Quality \& Reliability Management", Vol: 26, 2009, No: 6 (629-643)

[17] M. Down, Brozowski L., Younis H., Benedict D., Feghali J., Schubert M., Brender R., Gruska G., Vallance G., Krasich M., Haughey W., Potential failure mode and effect analysis (FMEA), 4th ed., Chrysler LLC Ford Motor Company General Motors Corporation, Germany, 2008.

[18] Y. Çeber, Hata türü ve etkileri analizi yönteminin (FMEA) üretim sektöründe uygulanması, Yüksek Lisans Tezi, Dokuz Eylül Üniv., Sosyal Bilim. Enst., İzmir, 2010.

[19] S. Karaoğlan, S. Şahin, DEMATEL ve AHP Yöntemleri İle İşletmelerin Satın Alma Problemine Bütünleşik Bir Yaklaşım, DSLR Kamera Örneği, İAD İşletme Araştırma Dergisi, DOI: 10.20491/isarder.2016.183, 2016.

[20] M. Yücel, A. Ulutaş, Çok Kriterli Karar Yöntemlerinden Electre Yöntemiyle Malatya'da Bir Kargo Firması İçin Yer Seçimi”, SÜ İIBF Sosyal Ve Ekonomik Araştırmalar Dergisi, 2014

[21] Y.Akyüz, M. Soba, Electre Yöntemiyle Tekstil Sektöründe Optimal Kuruluş Yeri Seçimi: Uşak İli Örneği, Int. Journal of Management Economics and Business, Vol. 9, No. 19, 2013

[22]İ. Ertuğrul, A. Özçil," Çok Kriterli Karar Vermede TOPSIS ve VIKOR Yöntemleriyle Klima Seçim”, Çankırı Karatekin Üniversitesi İktisadi ve İdari Bilimler Fakültesi Dergisi Y.2014, Cilt 4, Sayı 1, ss.267-282

[23]E. Demireli, "TOPSIS Çok Kriterli Karar Verme Sistemi: Türkiye'deki Kamu Bankaları Üzerine Bir Uygulama", Girişimcilik ve Kalkınma Dergisi, 2010, Cilt 5, Say11, s. 101-112. 